presented vitamin levels below the actual limits of $30 \mathrm{ng} / \mathrm{ml}$. These limits, used by most of the laboratories, tend to overestimate the vitamin $\mathrm{D}$ deficiency. References:

[1] Manson, JE. N Engl J Med 2018, DOI: 10.1056/NEJMoa1809944.

[2] Spector, TD. BMJ 2016: 355: i6183

[3] Wu, F. Osteoporosis International 2017; 28: 505-515.

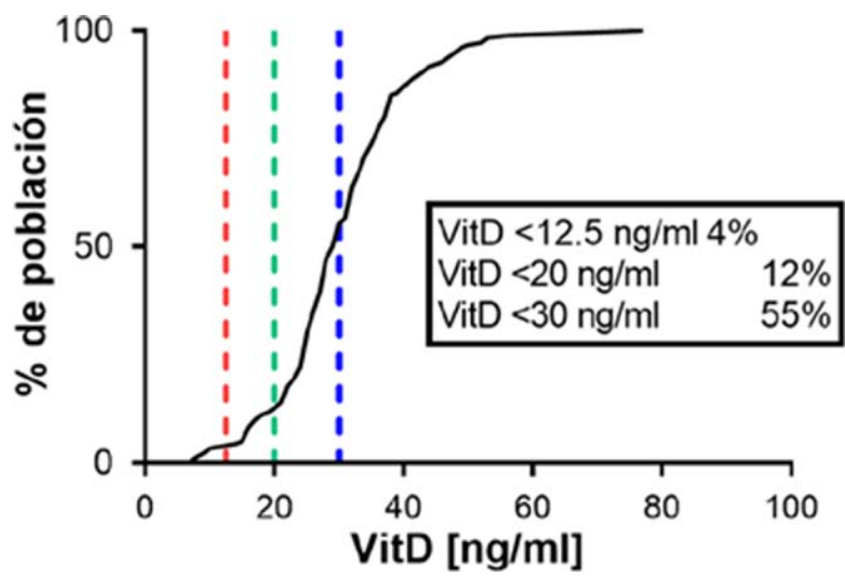

Disclosure of Interests: None declared

DOI: 10.1136/annrheumdis-2020-eular.4796

\section{AB0904 \\ PERSISTENCE AND REASONS FOR DISCONTINUATION OF DENOSUMAB IN PATIENTS WITH RHEUMATOID ARTHRITIS}

S. Mizuki ${ }^{1}$, T. Kai2, K. Mishima3, H. Ikeuchi3, K. Oryoji3. ${ }^{1}$ Matsuyama Red Cross Hospital, The Center for Rheumatic Diseases, Matsuyama, Japan; ${ }^{1}$ Matsuyama Red Cross Hospital, The Center for Rheumatic Diseases, Matsuyama, Japan; ${ }^{1}$ Matsuyama Red Cross Hospital, The Center for Rheumatic Diseases, Matsuyama, Japan

Background: Denosumab, a fully human monoclonal antibody to receptor activator of nuclear factor kappa B ligand, which inhibits osteoclast differentiation, activation and survival, not only increases bone mineral density but also inhibits the progression of bone erosion in patients with rheumatoid arthritis $(R A)^{1-3}$ ) Therefore, denosumab have been preferably prescribed for patients with RA recently. The persistence with denosumab, which is administered subcutaneously once every 6 months, was reported higher than with oral bisphosphonates ${ }^{4)}$, and in the prospective cohort studies, the persistence rate for one year was reported to be $82-95 \%{ }^{5-6)}$. However, there have been no report about the persistence in patients with RA treated with denosumab, moreover the reasons for discontinuation of denosumab.

Objectives: The aims of this single center retrospective cohort study were 1) to assess the persistence with denosumab in a routine clinical setting and 2) to identify the reasons of discontinuation in patients with RA. And we also reviewed the clinical outcomes of osteonecrosis of the jaw in patients with RA during denosumab treatment.

Methods: The present study is based on databases from our hospital, which include age, gender, date of injection of denosumab, as well as information on patients' characteristics. Patients were included in this study when denosumab were newly started at our department during the period from June 1, 2013 and September 30, 2017. In this study, persistence was defined as patients with an interval between injections of no longer than 6 months plus 8 weeks. Patients were followed until censoring (death, transferring to another hospital) or the end of the study (August 3, 2018).

We investigated reasons for the discontinuation of denosumab. Major reasons for the discontinuation of denosumab were classified as adverse event, anxiety over adverse events, patient's transfer or request, doctor's careless lack of refilling an injection, and other reason

We identified patients who had been diagnosed as osteonecrosis of the jaw, and demographic, pharmacological, and clinical data were collected from medical records.

Results: One hundred and seventy-five patients were identified. KaplanMeier analysis showed a slow decline of persistence after initiating denosumab therapy, dropping to 80.4 and $61.9 \%$ after 1 and 2 years of follow-up. When analyzing the reason of discontinuation as adverse events, the persistence rate of denosumab was at 89.4 , and $79.4 \%$ at 1 , and 2 years of follow-up, respectively.

During 2-year period, 72 patients discontinued denosumab. A total of 27 adverse events occurred, of which five events were osteonecrosis of the jaw. The other reasons for adverse event included death in four, fracture in three, and so on. Six patients discontinued due to anxiety over dental adverse event. Thirteen patients were in doctor's careless lack of refilling an injection

All five patients who were diagnosed as osteonecrosis of the jaw had received the treatment with prednisolone, and four were treated with biologic drugs. All patients stopped denosumab and switched to other drugs including teriparatide. All patients underwent surgical curettages of necrotic bone and cured.

Conclusion: Persistence of denosumab in patients with RA is comparable to that in postmenopausal women with osteoporosis. Dental screening and care should be important to continue denosumab treatment.

References:

[1] Cohen SB. Arthritis Rheum. 2008;58:1299-1309.

[2] Takeuchi T. Ann Rheum Dis. 2019;78:899-907.

[3] Ebina K. Osteoporos Int. 2018;29:1627-1636.

[4] Hadji P. Osteoporos Int. 2016;27:2967-2978.

[5] Silverman SL. Arch Osteoporos. 2018;13:85. doi:10.1007/s11657-018-0491-z [6] Hadji P. Osteoporos Int. 2015;26:2479-2489.

Disclosure of Interests: Shinichi Mizuki Speakers bureau: AbbVie, Asahi Kasei Chugai, Eli Lilly, Janssen, Mitsubishi Tanabe, Ono, Tatsuya Kai: None declared, Koji Mishima: None declared, Hiroko Ikeuchi: None declared, Kensuke Oryoji: None declared

DOI: 10.1136/annrheumdis-2020-eular.782

\begin{tabular}{|l|l}
\hline AB0905 & THE PREVALENCE AND RISK FACTORS OF \\
OSTEOPOROSIS IN PATIENTS WITH INFLAMMATORY \\
BOWEL DISEASES: A TUNISIAN STUDY
\end{tabular}

L. Mnif $^{1}$, H. Gdoura ${ }^{1}$, L. Chtourou ${ }^{1}$, A. Amouri ${ }^{1}$, M. Boudabbous ${ }^{1}$, N. Tahri ${ }^{1}$. ${ }^{1}$ University Hospital Hédi Chaker, Gastroenterology, Sfax, Tunisia

Background: Osteoporosis is as known a chronic complication of inflammatory bowel diseases (IBD). Its etiopathogenesis is often multifactorial.

Objectives: The aim of our study was to describe the prevalence of reduced bone mineral density and to identify risk factors of osteoporosis in patients with inflammatory bowel diseases.

Methods: This is a retrospective study over three years, collecting patients suffering from IBD and having benefited from a bone densitometry. We have specified for each patient the clinical data and the IBD characteristics. Bone minera density (BMD, g/ cm) was assessed by dual X-ray absorptiometry. Osteoporosis was diagnosed when BMD was 2.5 standard deviations below the mean peak value in young adults ( $T$ score,22.5 SD). Patients with other pathology that may change the bone metabolism were excluded.

Results: sixty-one patients were included with an average age of $38 \pm 13$ years [16-73]. The sex ratio M / F was 1.25 . $69 \%$ of patients had ulcerative colitis. The bone density profile was normal in $49.2 \%$ of the cases. Osteoporosis and osteopenia were noted in $13.1 \%$ and $37.7 \%$ of patients, respectively. Osteoporosis was associated with advanced age $(50.5 \pm 16.5$ years vs $36.26 \pm 12.93$ years $p=0.007)$ and longer course disease $(6.75 \pm 7,4$ years vs $2.5 \pm 4$ years; $p$ $=0.015)$. The cumulative dose of prednisone equivalent used in patients with osteoporosis was significantly higher than the other patients $(2775 \pm 3338 \mathrm{mg}$ vs $706 \pm 1449 \mathrm{mg} ; \mathrm{p}=0.003)$. Osteopenia was more frequently associated with crohn's disease $(58 \%$ vs $28.6 \% p=0.0029)$. There was no significant difference between the group with osteoporosis or osteopenia and the group with normal bone densitometry for sex and body mass index.

Conclusion: Osteoporosis during IBD is associated with advanced age, longer duration of illness and administration of high doses of corticosteroids. The high proportion of osteoporosis and osteopenia in our study underlines the importance of systematic BMD measurement in all IBD patients as a base for initiating the appropriate treatment

References:

[1] The prevalence and risk factors for osteoporosis in patients with inflammatory bowel disease. Miznerova E et al. Bratisl Lek Listy. 2013;114(8):439-45.

[2] Osteoporosis and inflammatory bowel disease: prevalence and risk factors in Tunisian patients. Boubaker J et al. Gastroenterol Clin Biol. 2003 Oct;27(10):901-7.

Disclosure of Interests: None declared

DOI: 10.1136/annrheumdis-2020-eular.1878

\section{AB0906 \\ PREVALENCE OF HYPOVITAMINOSIS D IN DIAGNOSTIC PATIENTS OF BREAST NEOPLASIA IS GREATER THAN EXPECTED FOR THE GENERAL POPULATION? SERIES OF 200 DIAGNOSTIC PATIENTS OF BREAST NEOPLASIA IN A TERTIARY HOSPITAL INITIATING TREATMENT WITH AROMATASE INHIBITORS}

D. Montero $^{1}$, O. Ibarguengoitia ${ }^{1}$, L. Vega ${ }^{1}$, C. García ${ }^{1}$, J. M. Blanco ${ }^{1}$, M. E. Ruiz ${ }^{1}$, A. R. Inchaurbe ${ }^{1}$, O. Fernandez ${ }^{1}$, I. Calvo ${ }^{1}$, C. E. Perez ${ }^{1}$, M. L. García Vivar $^{1}$, E. Cuande ${ }^{1}$, E. Galindez ${ }^{1}$, A. Bilbao ${ }^{2}$, I. Torre ${ }^{1} .{ }^{1}$ Basurto University 
Hospital, Rheumatology, Bilbao, Spain; ${ }^{2}$ Basurto University Hospital, Investigation, Bilbao, Spain

Background: In our population the prevalence of hypovitaminosis D is high. A recent cross-sectional observational study conducted in Spain shows that $63 \%$ of postmenopausal women who receive osteoporosis (OP) therapy and $76 \%$ who do not receive treatment had $25(\mathrm{OH}) \mathrm{D}$ levels below $30 \mathrm{ng} / \mathrm{mL}$.

The latest studies show a relationship between hypovitaminosis $\mathrm{D}$ and the development of systemic inflammatory and tumor diseases, determined by the presence of receptors in various tissues, including breast.

Objectives: To determine which levels of serum $25(\mathrm{OH}) \mathrm{D}$, and secondarily calcium, phosphorus, PTH and CTX, present 200 patients diagnosed with breast cancer and taking hormonal treatment, referred to a monographic OP consultation of a tertiary hospital for the assessment of their bone metabolism, and if these values differ from what is expected for the general population.

Methods: Retrospective cross-sectional study of 200 women diagnosed with breast cancer receiving treatment with aromatase inhibitors (Al), performed in a tertiary hospital. Blood levels of vitamin D, calcium, phosphorus, PTH and CTX have been collected, as well as other variables and risk factors

Results: 200 patients with a mean age of 64.8 years and an ED of 9.5 were collected. The median is 64.5 (Q1 58 and Q3 72).

The vitamin $D$ levels presented by the study patients were $<10 \mathrm{ng} / \mathrm{mL}$ in 13 patients $(6.67 \%), 11-20 \mathrm{ng} / \mathrm{mL}$ in $50(25.64 \%), 21-30 \mathrm{ng} / \mathrm{mL}$ in $68(34.87 \%)$, $31-70 \mathrm{ng} / \mathrm{mL}$ in $62(31.79 \%)$, and $>70 \mathrm{ng} / \mathrm{mL}$ in $2(1.03 \%)$. This implies that in $67.18 \%$ of the patients they had values below the optimal range.

$92.31 \%$ of patients (180) presented PTH values within the normal range and only $7.69 \%$ presented values above normal.

The serum calcium and phosphorus levels of the patients selected for the study had ranges within normal $(99.49 \%)$ except 1 case that presented high values $(0.51 \%)$ for both.

The values of CTX (carboxyterminal telopeptide used as a marker of bone resorption) were in the normal range in $81.96 \%$ of patients (159), low values in $0.52 \%$ (1) and values above the normal range by $17.53 \%$ (34).

Conclusion: The prevalence of insufficient levels of vitamin D in our study (Breast cancer $+\mathrm{Al}$ ) is not greater than that estimated for the general population according to various studies.

Our study found that $67.18 \%$ of patients (2/3 of the selected population) had values below those considered optimal ( $<30 \mathrm{ng} / \mathrm{mL}$ ) and $32 \%$ had values $<20$. Only $7.69 \%$ of the patients presented PTH values above the normal range.

In $82 \%$ of patients, CTX used as a marker of bone resorption had normal values. References:

[1] Quesada Gomez JM, Díaz Curiel M, Sosa Henríquez M, Malouf-Sierra J, Nogués-Solan X, Gómez-Alonso C, et al. Low calcium intake and insufficient serum vitamin D status in treated and non-treated postmenopausal osteoporotic women in Spain. J Steroid Biochem Mol Biol. 2013;136:175-7.

[2] Jian Sun et al., Vitamin D receptor expression in peripheral blood mononuclear cells is inversely associated with disease activity and inflammation in lupus patients; Clinical Rheumatology (2019) 38:2509-2518

Disclosure of Interests: None declared

DOI: 10.1136/annrheumdis-2020-eular.5595

\section{AB0907 BONE METABOLISM ASSESSMENT IN PATIENTS WITH RECENT DIAGNOSIS OF GIANT CELL ARTERITIS}

A. Nack ${ }^{1}$, I. Casafont-Solé ${ }^{1}$, L. Mateo ${ }^{1}$, S. Holgado Pérez ${ }^{1}$, M. Martínez-Morillo ${ }^{1}$, M. Aparicio Espinar ${ }^{1}$, A. Riveros ${ }^{1}$, C. Sanguesa ${ }^{1}$, Á. Prior-Español ${ }^{1}$, M. Aparicio Rovira ${ }^{1}$, A. Olive ${ }^{1}$, L. Gifre ${ }^{1} .{ }^{1}$ Hospital Germans Trias i Pujol, Badalona, Spain

Background: There are several studies assessing bone mass and osteoporosis (OP) development of patients with giant cell arteritis (GCA) during glucocorticoid treatment, however data at time of diagnosis is scarce.

Objectives: To analyze bone metabolism, bone mineral density (BMD) and trabecular microarchitecture by measuring trabecular bone score (TBS) in patients with recent diagnosis of GCA.

Methods: Retrospective observational study in which we included all patients with GCA and bone metabolism assessment at diagnosis. We recorded: risk factors for OP (previous fractures and anti-OP treatments), bone metabolism (calcium, phosphate, PTH, 25-vitaminD [25-OHD]) and the DXA results (Lunar, DPX) at the time of diagnosis and during the follow-up. The statistic analysis was made with SPSS.

Results: 36 patients ( $27 \mathrm{~W}$ : $9 \mathrm{M}$ ) with a mean age of $76 \pm 9$ years were included. The clinical characteristics of the GCA at diagnoses were: headache (81\%), constitutional syndrome $(58 \%)$, allodynia $(42 \%)$, visual loss $(42 \%$, binocular in 2 patients), jaw claudication (39\%), polymyalgic syndrome (28\%), amaurosis fugax $(25 \%)$ and lingular necrosis $(n=1,3 \%)$. Additional diagnosis tests included: temporal biopsy ( $86 \%$, being pathologic in $55 \%)$, temporal ultrasound $(97 \%$, pathologic $34 \%)$, extra-cranial arteries ultrasound $(81 \%$, pathologic $7 \%$ ) and PET/CT (19\%, pathologic $86 \%)$. Up to $61 \%$ received three metilprednisolone bolus (mean dose $1700 \mathrm{mg}$ ). 7 patients (19\%) had previous OP and 3 had already suffered a fragility fracture (Colles, vertebral and femur). Only 4 patients were receiving anti-OP treatment (2 oral bisphosphonate, 2 zoledronate).

At time of diagnosis of GCA, the mean of $250 \mathrm{HD}$ was $17 \pm 13 \mathrm{ng} / \mathrm{mL}(88 \%,<30)$. BMD showed low bone mass in $80 \%$ of patients ( $47 \%$ with OP, $33 \%$ osteopenia). The mean TBS was $1.026 \pm 0.098$ and up to $38 \%$ showed poor bone microar chitecture [values <1.23]). No significant differences were observed between patients with or without TBS $<1.23$. Up to $94 \%$ of patients received anti-OP treatment ( 26 zoledronate, 6 oral bisphosphonate, 1 denosumab, 1 teriparatide). 3 patients had incidental fractures during the follow-up, however no relation was found with BMD or TBS.

Conclusion: Low bone mass and vitamin $\mathrm{D}$ insufficiency are frequent in patients with recent diagnoses of GCA and up to $38 \%$ have poor bone microarchitecture at baseline. Thus, it's important to perform a bone mass assessment in all patients with recent diagnose of ACG and initiate therapeutic or preventive anti-OP treatment if required.

Disclosure of Interests: None declared

DOI: 10.1136/annrheumdis-2020-eular.3047

\section{AB0908 $\quad$ ASSESSMENT OF THE IMPACT OF THE LEAN MASS WITH BODY COMPOSITION BY DUAL-ENERGY X-RAY ABSORPTIOMETRY ON THE BONE MINERAL DENSITY}

\section{Nikolov ${ }^{1}$, N. Nikolov ${ }^{1}{ }^{1}$ UMBAL Dr Georgi Stranski, Pleven, Bulgaria}

Background: Lean mass, mainly composed of muscle, has been correlated to bone mineral density (BMD) [4]. Studies reported that lean mass has an important impact on BMD not only in young women but also in postmenopausal women [1]. High lean mass is more favorable for the BMD than low lean mass. Some studies suggested that genetic factors responsible for both lean mass and BMD are shared [3]. Low muscle mass and low BMD could impair the quality of the patient's life [2, 5]. Objectives: The aim of this study is to assess the impact of the lean mass with body composition by dual-energy $\mathrm{X}$-ray absorptiometry on the bone mineral density. Methods: 107 women underwent body composition analysis by dual-energy X-ray absorptiometry (DXA). Lean mass in $\mathrm{kg}$ and BMD in $\mathrm{kg} / \mathrm{cm} 2$ were analyzed. Nor mal BMD was defined as T-score $>-1.0$ standard deviation (SD). Osteopenia was defined as T-score between -1.0 SDs and -2.5 SDs and osteoporosis was defined as T-score $\leq-2.5$ SDs.

Results: The mean age of the women was 57 years (yrs.) \pm 11 yrs. (range $41 \mathrm{yrs}$. $-80 \mathrm{yrs}$.). Subjects had mean weight of $75 \mathrm{~kg} \pm 12 \mathrm{~kg}$ (range $50 \mathrm{~kg}-110 \mathrm{~kg}$ ) and mean height of $156 \mathrm{~cm} \pm 9 \mathrm{~cm}$ (range $151 \mathrm{~cm}-172 \mathrm{~cm}$ ). 73/107 women $(68.2 \%)$ were with normal BMD, 24/107 women (22.4\%) were with osteopenia and 10/107 women $(9.4 \%)$ were with osteoporosis. Lean mass differed significantly between the groups $(p=0.000)$. Women with normal BMD had the highest mean lean mass $(58.47 \mathrm{~kg})$ and the mean lean mass of the women with osteopenia and osteoporosis decreased as follow: $47.56 \mathrm{~kg}$ for women with osteopenia and $36.22 \mathrm{~kg}$ for women with osteoporosis.

Conclusion: Women with osteoporosis have the lowest lean mass compared to the women with osteopenia and osteoporosis.

References:

[1] Ilesanmi-Oyelere BL, Coad J, Roy N, Kruger MC. Lean Body Mass in the Prediction of Bone Mineral Density in Postmenopausal Women. Biores Open Access. 2018;7(1):150-158. Published 2018 Oct 10. doi:10.1089/ biores.2018.0025.

[2] Kirilov N., Vladeva SG, Kirilova E. Assessment on the Improvement of the Quality of Life after One Year of Regular Physical Activity and Treatment in Patients with Postmenopausal OsteoporosisCOR 2017: 19th International Conference on Orthopedics and Rheumatology Miami, USA March 9 - 10, 2017, WASET, Paper Code 17US030051.

[3] Nguyen TV, Howard GM, Kelly PJ, Eisman JA. Bone mass, lean mass, and fat mass: same genes or same environments? Am J Epidemiol. 1998 Jan 1;147(1):3-16.

[4] Patel HP, Dawson A, Westbury LD, et al. Muscle Mass, Muscle Morphology and Bone Health Among Community-Dwelling Older Men: Findings from the Hertfordshire Sarcopenia Study (HSS). Calcif Tissue Int. 2018;103(1):35-43. doi:10.1007/s00223-018-0388-2.

[5] Kirilova E, Kirilov N, Vladeva S. A study on the physical activity in women with decreased bone mineral density. Abstract book $13^{\text {th }}$ science conference MC, Pleven

Disclosure of Interests: None declared

DOI: 10.1136/annrheumdis-2020-eular.4525

\section{AB0909 \\ TREATMENT WITH DENOSUMAB IN GLUCOCORTICOSTEROID-INDUCED OSTEOPOROSIS IN PATIENTS WITH RHEUMATOID ARTHRITIS}

M. Osipyan ${ }^{1}$, M. Efraimidou², S. Bazeyan ${ }^{2}$, A. Antikyan², V. Vardanyan², K. Ginosyan ${ }^{1}{ }^{1}$ Yerevan State Medical University, Rheumatology, Yerevan, Armenia; ${ }^{2}$ Yerevan State Medical University, Yerevan, Armenia 